\title{
Experts by Experience as Contributors to Research and Development in a Corporate Context
}

\author{
Susanne JACOBSON ${ }^{\mathrm{a}, 1}$ \\ ${ }^{\text {a }}$ Research, KONE Corporation, Finland
}

\begin{abstract}
This paper presents the findings of a user study conducted at a company, a global leader in its industry, in order to engage experts by experience in the research and development of the company's future products. People who have lifechanging experiences such as being ill or having a disability, and who are trained to consider their environment in terms of those experiences, can be called experts by experience. They can be inventive in creating solutions to the challenges of an inaccessible environment. Currently, their expertise is primarily used by the public sector, mainly in welfare and health-related initiatives. The corporate sector seems to have not yet actively engaged them. This study adopted a design research approach and applied a case study method to a research and development project conducted at a company. The user study comprised experts by experience testing a physical prototype that had digital content, by thinking aloud, interacting and participating in a design game. The aim was to understand the strengths, opportunities and development needs of the prototype, as well as to gain the experts' insights into future requirements and how to meet them with similar products. The study resulted in usability-, appearance- and feel-related product qualities, as well as ideas regarding the product's potential applications and digital content. The findings suggest that trained experts by experience can provide a company with information that could act as design drivers that benefit strategic development. Due to the inclusion and empowerment of users, as well as fostering their equality, engaging experts by experience in research and development could also be considered to be an example of corporate social sustainability and responsibility.
\end{abstract}

Keywords. Case study, design research, experts by experience, research and development, social sustainability

\section{Introduction}

\subsection{The Corporate Context}

$\mathrm{InSCOPE}^{2}$ was a joint multinational and cross-industrial project funded by the EU Horizon 2020 research and innovation programme from 2017-2020. The project aimed to establish an open access pilot line service for hybrid printed electronics. It brought

\footnotetext{
${ }^{1}$ Research, KONE Corporation, Keilasatama 3, 02150 Espoo, Finland; E-mail: susanne.jacobson@kone.com.

${ }^{2}$ International Smart Collaborative Open-access Hybrid Printed Electronics pilot line.
} 
together several research and industrial partners representing the automotive, healthcare, smart packaging and building sectors. [1]

One of the partners in the project was KONE Corporation (later KONE), whose mission is "to improve the flow of urban life" and whose vision is "to create the best People Flow ${ }^{\circledR}$ experience". The company is a global leader in the elevator and escalator industry. [2] In the InSCOPE project, KONE aimed to demonstrate interactive media surfaces in elevators at a more affordable cost. A total of three subsequent prototypes were developed in collaboration with the project partners. The final prototype, an elevator car fitted with an interactive media surface, was tested with experts by experience. In this paper, that study and its findings are presented and explored as an example of user involvement and a potential form of social sustainability in corporatelevel research and development.

\subsection{Experts by Experience}

Experts by experience are people who have knowledge of living with life-changing experiences such as illness or disability. In addition, they have undergone training. They are trained to consider their environment with respect to their experience. [See e.g. 3] Their feedback can be valuable in developing products, including services, spaces and systems that are inclusive and benefit diverse users. They may even have invented solutions themselves. For example, some people with a disability have customised existing assistive technology and applied ready-made products to assistive purposes of use in order to have solutions that better meet their needs [4]. Such inventions embody qualities that can be applied to the development of other more mainstream and inclusive products.

The experts by experience activity has its roots in the voluntary sector and peer support. Experts by experience can work within their own reference group or outside it in collaboration with other professionals. [5] With respect to their expertise, they can act as educators, developers, spokespersons, evaluators, instructors and support persons [5, pp. 19-29]. They can also be openers, role models, peers and mediators of experience [6, pp. 25-29].

Engaging experts by experience in development aims to foster equality and empowerment, and it can be rehabilitative. However, involving experts by experience also has its challenges. Experts by experience have a twin role as rehabilitees, users and customers of welfare services and benefits, as well as independent actors and receivers of earned compensations. This may result in conflicting situations in which their position is ambiguous. [5, 6] Thus, their role has sometimes been reduced to a mere "formal quota" in which involving experts by experience has been a means of executing the politics of participation [6, pp. 29-32]. Some of the conflicting situations have revealed that public services are currently rather system-centred [5]. There seems to be a need for a more user- and customer-centred type of approach.

Currently in Finland, experts by experience have been mainly engaged in the development of public welfare and health [see e.g. 7], often related to mental health care and substance abuse rehabilitation [see e.g. 5]. Also, patient organisations have a history of using experts by experience $[8$, p. 6]. In addition to the public sector, private sector companies can benefit from involving experts by experience, for example, in tasks related to product development. Equally, engaging experts by experience in private sector companies could act as something that sheds light on the issues that are important to customer-centred practices in general and that are currently missing in some of the 
services provided by the public sector. In this study, experts by experience took a role in which they represented a group of people with extreme accessibility requirements, and evaluated a product with respect to these requirements, while still striving to achieve an inclusive outcome.

\subsection{Social Sustainability}

In this exploratory case, the phenomenon of involving experts by experience is also considered from the perspective of corporate social sustainability. There are numerous definitions of social sustainability although none of them have been universally adopted. However, justice, equality and the possibility of influencing are often commonly associated with it $[9, \mathrm{pp} .416,418]$. Social sustainability also relates to social responsibility, social inclusion, social empowerment, and, more widely, to humancentredness. According to the ISO standard for human-centred design for interactive systems ${ }^{3}$, "a human-centred approach results in systems, products and services that are better for the health, well-being and engagement of their users, including users with disabilities" [10, p. 20].

The United Nations, which refers to social sustainability as "identifying and managing business impacts, both positive and negative, on people" [11], has established 17 sustainability goals, of which the first six concern social sustainability. The social sustainable development goals set by the United Nations aim to achieve a better and more sustainable future for all in terms of poverty, inequality, climate, environmental degradation, prosperity, peace and justice [12]. As a member of the UN Global Compact, KONE is dedicated to addressing social, ecological and economic sustainability, as well as reporting on its efforts. KONE is committed to an ethically and socially responsible way of conducting business throughout its value chain. [13] In this paper, social sustainability is viewed in relation to the company's research and development, not, for example, human resources management.

\section{Approach}

In the InSCOPE project, KONE conducted qualitative design research. Whereas quantitative data tends to focus on what, when and how much people do something, qualitative data helps understand why and how they do, or do not, do something. Qualitative data is particularly useful for concept design ${ }^{4}$ as the findings can sometimes readily provide insights into improving current products and envisioning and creating new products in a user-centred way.

The aim of the study was to involve participants with diverse abilities, characteristics and dimensions in order to provide rich information related to the strengths, opportunities and development needs of the prototype. The idea, deriving from the objectives of Universal Design, Inclusive Design and Design for $\mathrm{All}^{5}$, was that charting the

\footnotetext{
${ }^{3}$ Initially, ISO 13407:1999.

${ }^{4}$ Concept design refers to a product design type of activity, although, with no immediate demand for entering the market or production instructions. During the concept design phase, the main design guidelines are defined. Concept design that is based on research can benefit discussion and decision-making, as well as help define a strategy. [14, pp. 24, 26, 29]

${ }^{5}$ Universal Design, Inclusive Design and Design for All have historical differences but share the same objective of creating an inclusive and universal environment that is usable for all.
} 
requirements of so-called extreme users would also fulfil the requirements between the extremes and result in solutions that could be used by the widest range of people, to the greatest extent possible, and without the need for adaptation [see e.g. 15].

In the present study, experts by experience with a disability would be likely to provide information on accessibility and, in particular, the multisensory qualities that contribute to it. Accessibility is a fundamental property of elevators, which are a key part of KONE's product offering. Elevators are not only meant to be used by everyone but are an assistive means of transportation for those who cannot use the alternatives: stairs and escalators. The importance of accessibility for interactive media surfaces is also likely to increase in the near future as the European standard [16] requires that in Europe, all information and communication technology, whether products or services, procured by the public sector, is accessible. However, it is also important to take into account other qualities because products that are solely assistive and accessible can be experienced by users as stigmatising if they emphasise and misrepresent their disability [4]. In identifying such qualities, people who are accustomed to using assistive and accessible products can provide information on their shortcomings, as well as insights into developing them.

\subsection{The User Study ${ }^{6}$}

The prototype, an elevator car with an interactive media surface, was tested by experts by experience who had physical and visual impairments. Even though they had previous experience of considering the built environment in terms of their respective conditions and, for example, using elevators and digital media, they did not, however, have prior experience of products that would combine these two.

The experts were recruited by two different networks. Three of the experts were women and one man, between 39-49 years of age. Two of them used a powered wheelchair, one occasionally used a manual wheelchair, although not in the user study. One of them had prosthetic legs, visual impairments and used a crutch. The users of a powered wheelchair could not fully move their hands and one of them had a personal assistant to help them. The study was organised at the company's factory premises and comprised two parts: The first part involved the experts testing the prototype and the second part was a design game. The two methods were chosen in order to have complementing data and to enable a comprehensive understanding of both user experience and insights. All experts signed a consent form to participate in the study. They received a gift voucher for their input.

The prototype portrayed different combinations of colours, lights and their movements (Figure 1). The elevator car itself did not move, nor did it have an elevator's user interface. The changing colours were yellow, orange, red, violet, blue and green. An earlier version of the prototype had included only a few colours, which had not been considered sufficient. Previous research has shown that colours can have ambiguous effects and studies tend to address only a very limited number of colours [17, p. 57]. As there was not sufficient time to include all colours in the user study, six colours that were

\footnotetext{
6 The findings of the user study have also been included in an unpublished report of the InSCOPE project. After writing and submitting the research paper at hand, and the postponement of the conference due to the COVID-19 pandemic, the findings have also been utilised in a Master's thesis and two submitted, not yet accepted, conference papers. All of them have approached the user study and its findings from different standpoints than this paper.
} 
considered to have enough variety and clarity were chosen. The movements comprised various shapes from points to waves, which emerged and moved in different ways and directions. Due to the moving colours and lights, before the study it was verified that none of the participants would experience migraine or epilepsy.
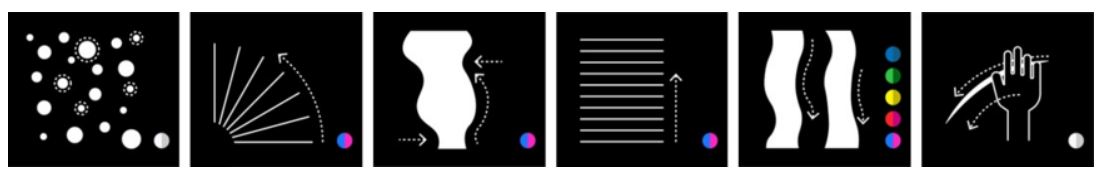

Figure 1. The different combinations of colours, lights and their movements portrayed by the prototype.

In the first part of the user study, the experts' first impressions of the prototype were observed. Each participant was asked to think aloud and describe their experience and how it made them feel (Figure 2). The participants responded in their native language, which was Finnish.

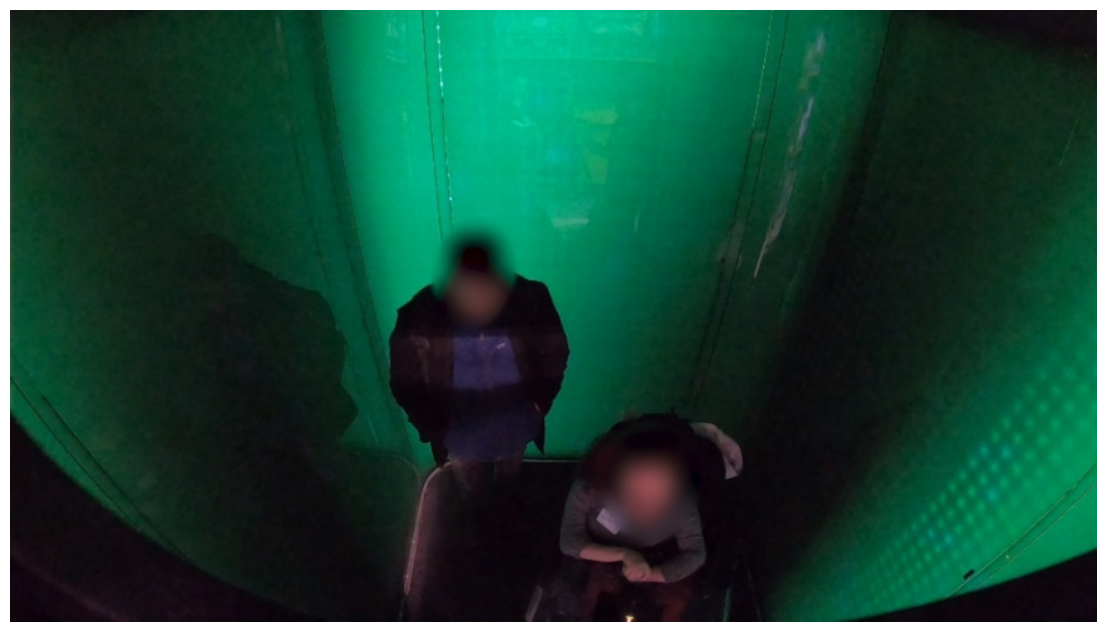

Figure 2. A participant with her personal assistant thinking aloud when testing the prototype.

All sessions were audio and video recorded, and two kinds of notes were also written. The analysis of the material was data-driven in the original language.

The objective was to understand how the experts perceived the various colour, light and movement combinations, and how they felt about them. Questions were asked when the experts' explanations about something needed to be clarified. After initially being shown the prototype, the experts were able to interact with it by controlling the surface using bodily gestures (Figure 3 ). 


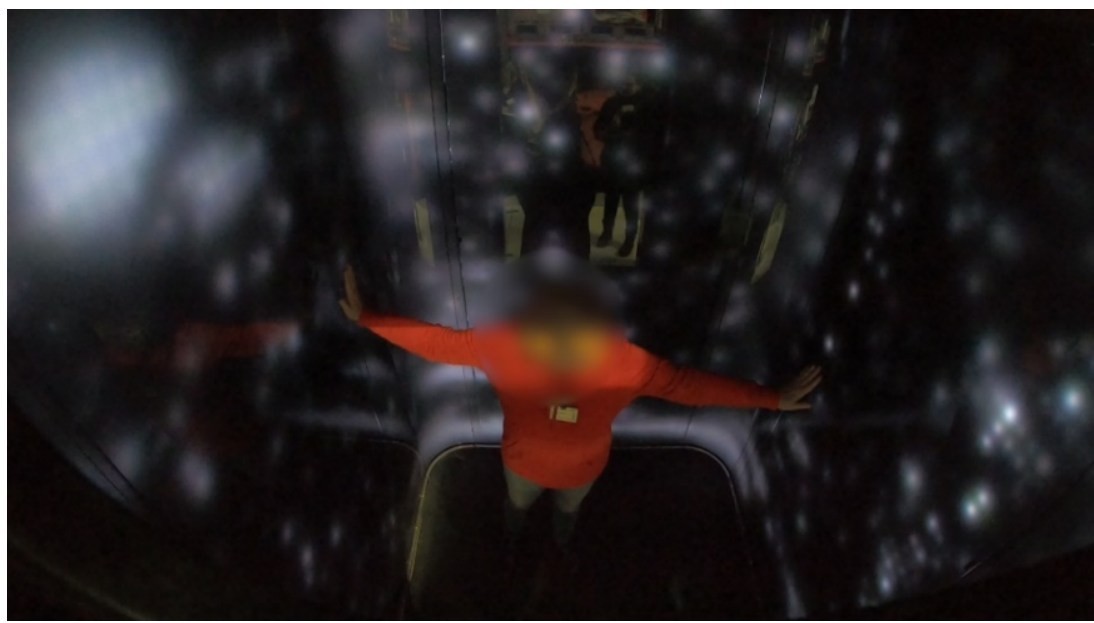

Figure 3. A participant interacting with the prototype.

In the study, one researcher (the author of this paper) was standing behind the participant observing and asking questions when needed; another researcher was focusing on the overall situation and the participant's expressions and gestures slightly further away. A third researcher was standing behind the prototype and controlling its colours, lights and their movements.

The second part of the user study consisted of a design game. The game was conducted in the experts' native language, Finnish, with each expert individually, and included interview questions. This made it possible to have both parts of the user study in a row with each participant, and no-one had to wait for other participants to complete their tasks. However, it should be noted that a joint design game involving all the participants might have led to different insights, depending on the group dynamics.

The design game consisted of tasks that required insights from the experts about similar media surfaces to the prototype in general, as well as experience of and desires related to such surfaces. The game was supported by image cards. The cards included various themes, such as technology, nature, politics, animals, emotions, relationships, food, activities, mobility, health and materials, representing different aspects of life as widely as possible. (Figure 4.).

In the design game, each participant was first asked about the places they visited most frequently, and what kinds of everyday needs and wishes they had with respect to them. The experts also identified places they would like to visit, but had not for some reason or other. The aim was to create a context for recognising challenges and identifying solutions. The experts were then asked to ideate how media surfaces could meet the identified requirements. They also considered the contents that they would like media surfaces to include, and where the surfaces would be located. Finally, the experts were asked what they thought about media surfaces that were able to measure different factors and collect data. The purpose of the design game was to recognise new, userinspired opportunities for future products similar to the prototype. All the design game sessions were audio recorded and the recordings transcribed verbatim. The analysis was data-driven, in the original language, using an affinity diagram (Figure 5). 


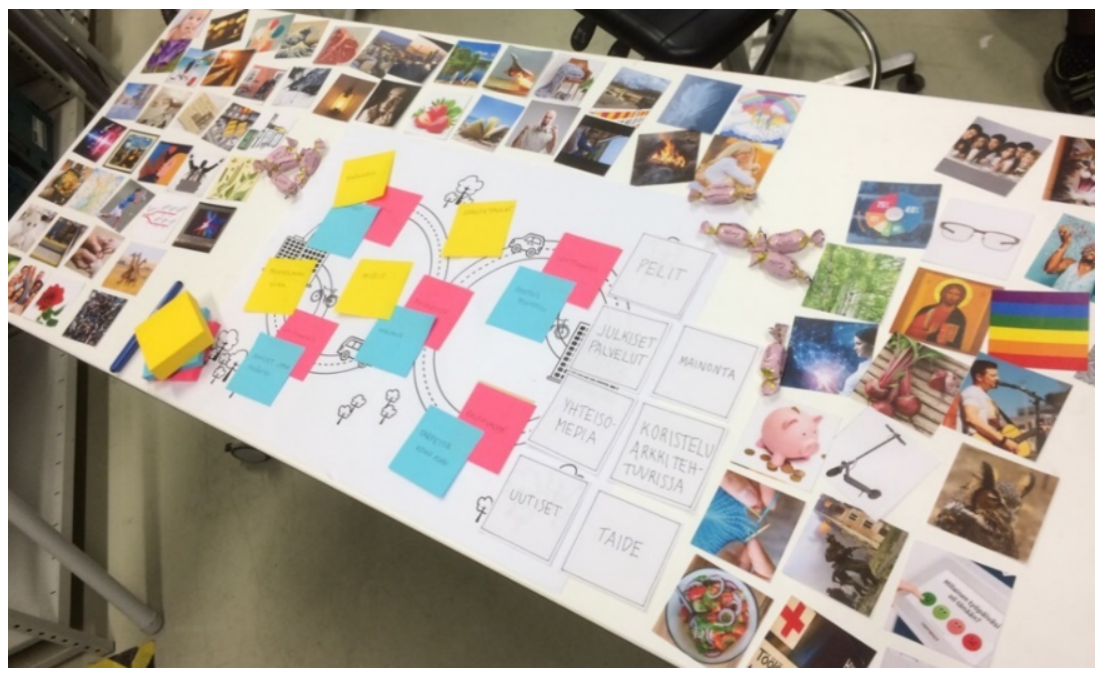

Figure 4. The design game.

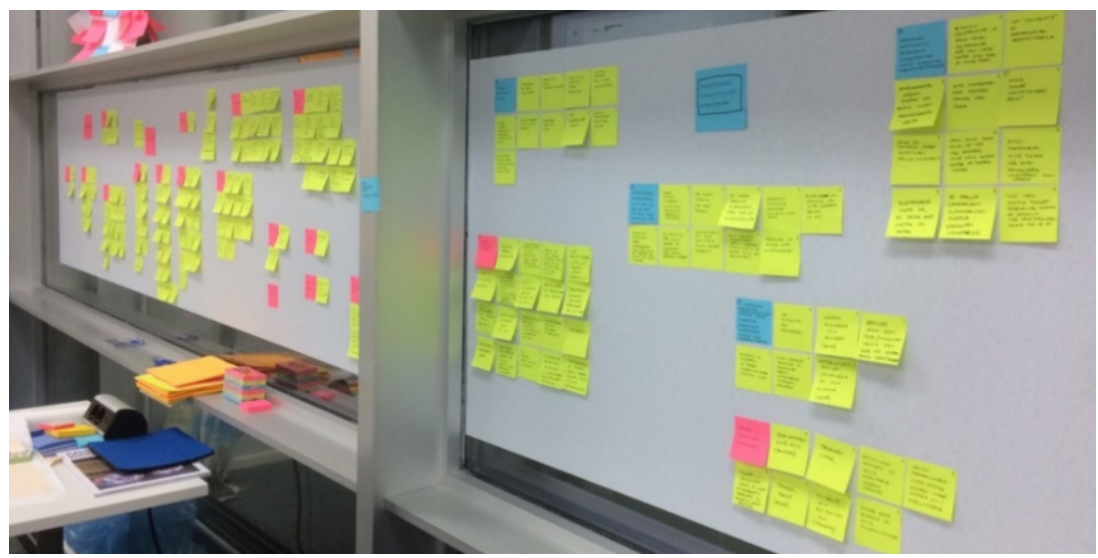

Figure 5. Structuring the material.

In the following, the findings of the user study are rigorously reported in order to demonstrate the variety of insights provided by the experts by experience, when they tested the prototype.

\section{Results}

\subsection{Colours, Lights, Movements and the Associations They Create}

When entering the prototype, some of the experts stated that it felt like they had arrived at a theatre, or under a night sky, as the white twinkling points resembled stars (Figure $6)$. 


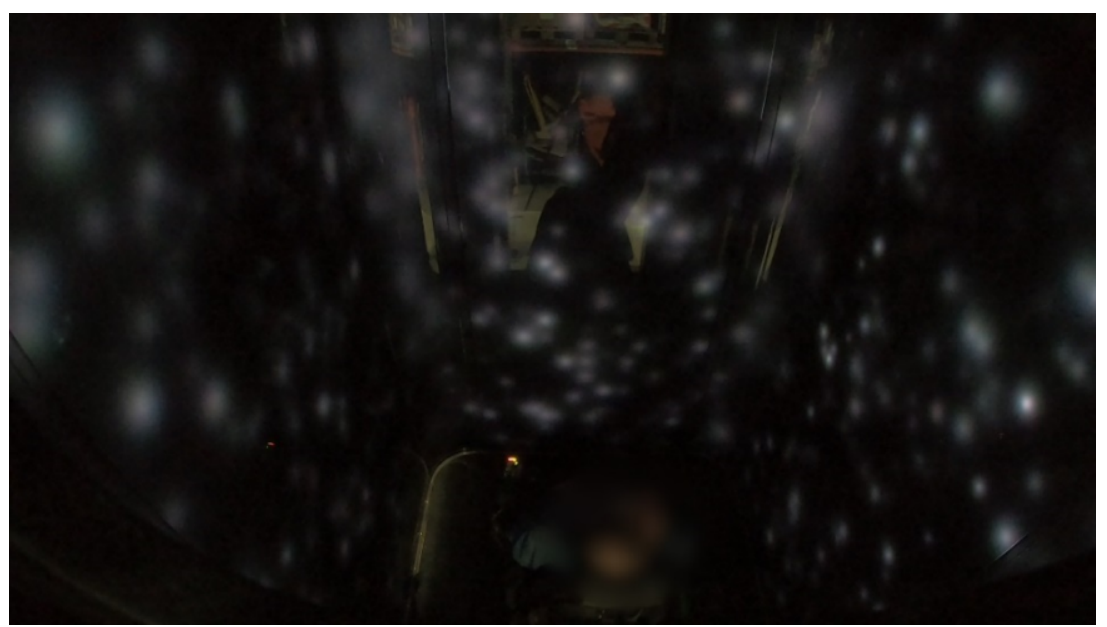

Figure 6. The starting view at the point that each participant entered the prototype.

The experts felt that the bluish colours had a calming, even cold effect, but in a positive sense. Depending on their type of movement, they were associated with space and sky, or being in an aeroplane above the clouds, on top of a tall building, or underwater and inside an aquarium. One of the experts even tried to recognise the shapes of various fish, as well as also other shapes (Figure 7).

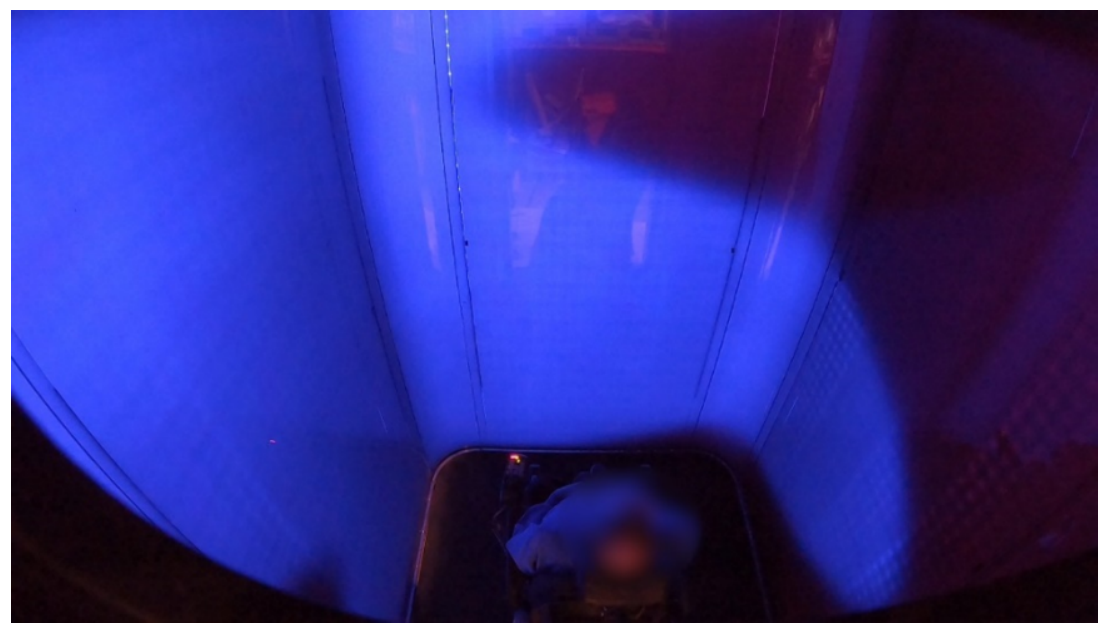

Figure 7. A participant trying to recognise shapes.

The reddish colours were perceived as being warmer and energetic. They were associated with partying, being in a disco, particularly when the colours were constantly changing (Figure 8). The expert with visual impairments suggested that the reddish or pinkish colours would work well as text against a dark background. 


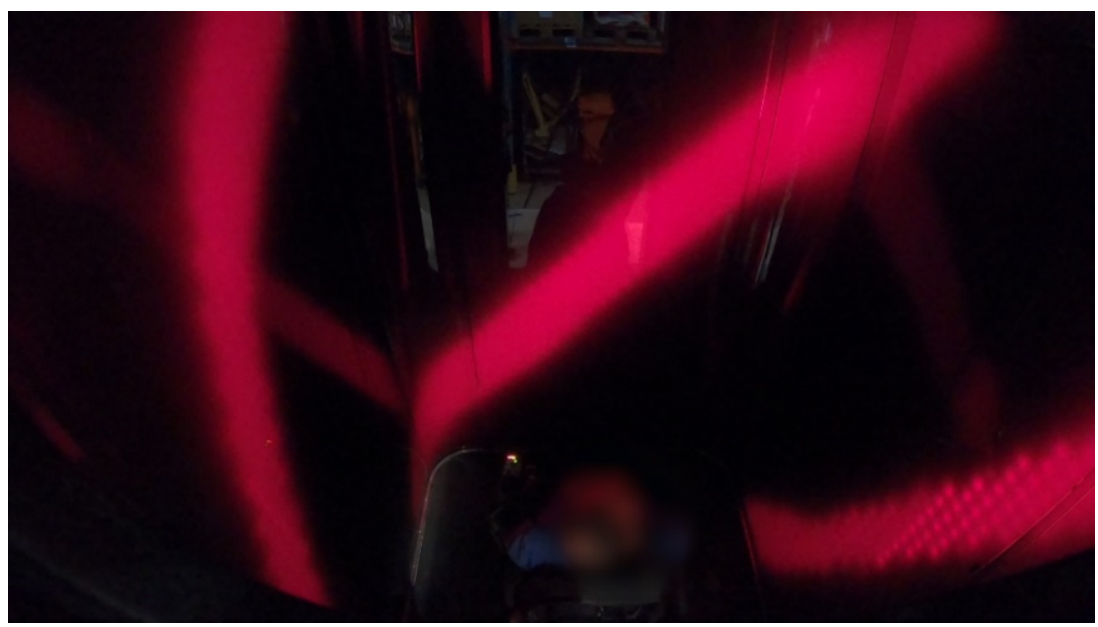

Figure 8. The moving colour red was associated with partying.

The tinted yellow colour was considered to be particularly pleasant (Figure 9). It was associated with warmness and the sun. According to one expert, it resembled summer and being at the beach, as if looking through sunglasses. The same colour reminded another expert of a bowling alley, although she could not explain why.

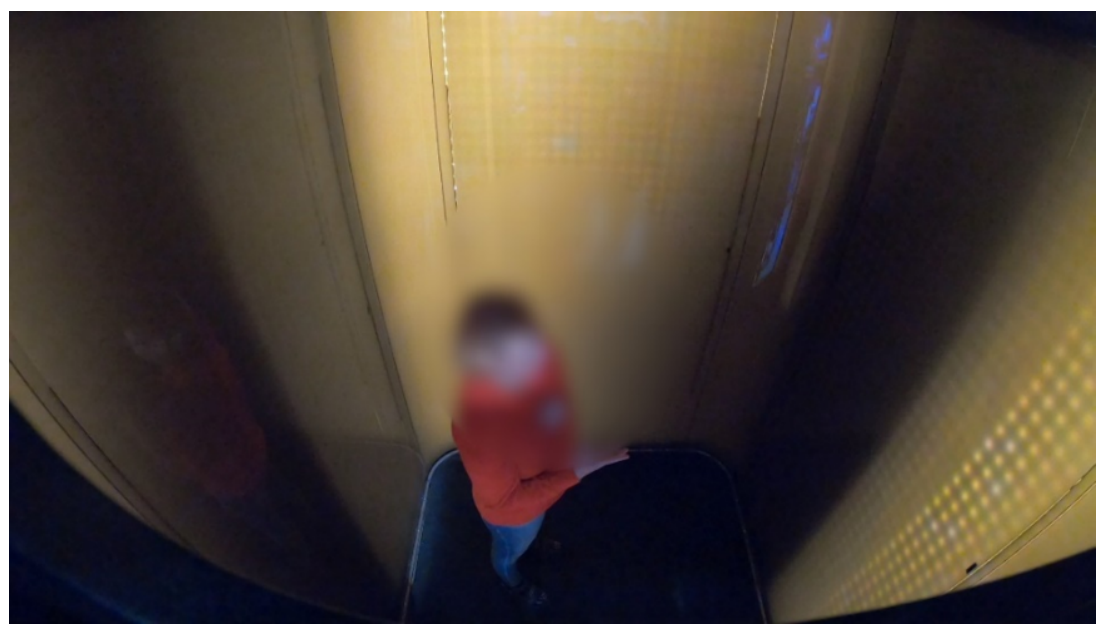

Figure 9. The tinted yellow colour that the experts perceived as being particularly pleasant.

For most of the experts, slower and upward or downward movements (Figure 10) were more pleasant and relaxing than faster, lateral or zigzag movements. The latter were regarded as restless and unpleasant by some of the experts, who thought they might even cause dizziness. At some point, the personal assistant of one of the experts had to step out of the prototype because they felt unwell. According to the experts, the movements that were perceived as negative should be more predictable and offer a sense of direction. Only the expert with visual impairments liked the lateral movements more. Nevertheless, she pointed out that it would be difficult to walk inside the prototype due to the moving 
colours and lights. However, none of the experts felt that the prototype and its colours, lights and their movements were disturbing or claustrophobic.

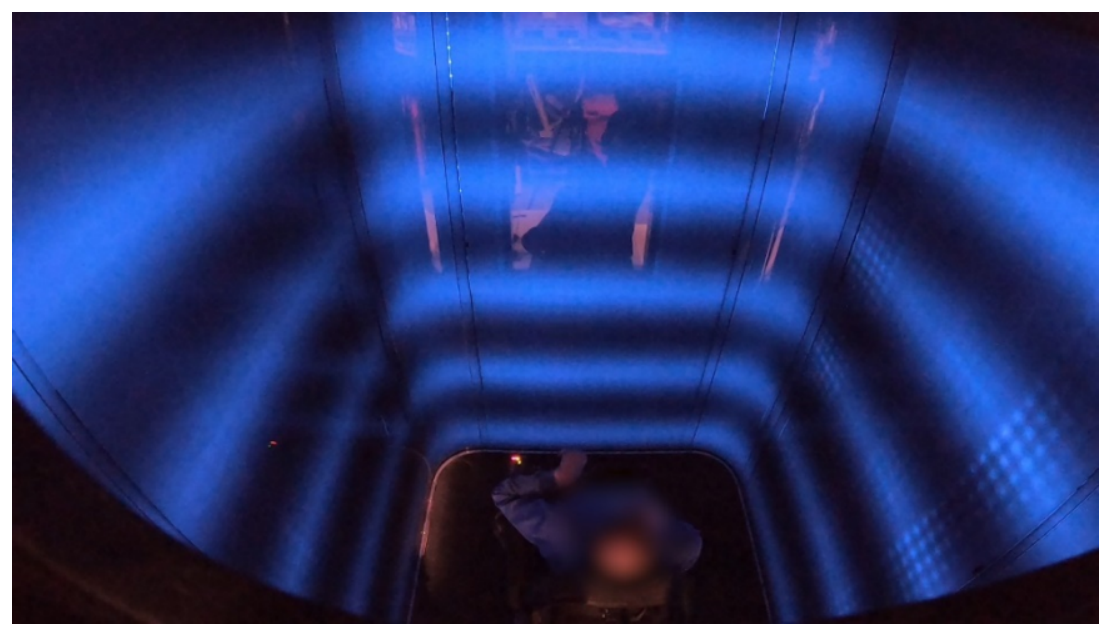

Figure 10. Upward or downward movements were more pleasant than lateral movements.

During the thinking aloud task, the media surface in the elevator car was further associated with a hotel, spa and an amusement park. Even though the surface was inside an elevator car, it seemed to be the upward and downward movements of the colours and lights that made the prototype actually resemble an elevator. The different colour, light and movement combinations also evoked associations of waves, rain drops, a moving rainbow and a lightshow (as an environmentally-friendly alternative to fireworks). In general, the media surface was regarded as temperate, yet lively, and even "cool".

\subsection{Accessibility and Interaction}

All the experts took accessibility into account both in the thinking aloud task and the design game. It became clear that the built environment at large is not yet as accessible for them as it should be. One of the experts, who used a powered wheelchair, was particularly concerned about accessibility. She was delighted when she realised that there was also sufficient space for her personal assistant inside the prototype, and that she could turn around, even in a powered wheelchair. The round corners in the elevator car and the wide entrance gave her even greater accessibility. She was interested in the kind of door that would be used in the final product and where, as well as which height the user interface would be located. She suggested that a mirror should be installed on the opposite wall, as it would help her (and other wheelchair users) to enter and exit the elevator. The expert with visual impairments was surprised to notice how much colour temperature and contrast can influence the experience. For her, the light blue colour was the most pleasant and usable.

In the interaction task, the experts were asked to "use" the prototype. Some of them soon realised the possibility of controlling the movements by hand, while others needed to be given hints. The surface was initially dark, which raised questions about whether or not it worked. Some of the experts tried to use the surface like a touchscreen, until they realised that the interaction did not require it. One expert tried to "wake up" the 
prototype by calling out "Illuminate!". All of the experts regarded the opportunity of interacting with the media surface as exciting and playful. They associated this with drawing, which was considered fun, or painting as a way of channelling their creativity. The expert with visual impairments became almost mesmerised when controlling the movement by hand. With only one seeing eye, which was actually sensitive to light, she closely followed how the light moved according to her hand movements.

Controlling an interactive media surface in various ways, not only by hand, and using multisensory cues were regarded as being inclusive, i.e. usable for all people. Some of the experts suggested that operating the surface with a voice could also be a potential solution. For the expert who used a powered wheelchair and could not fully move her hands, a voice would be the best way of controlling the prototype in its current form. She also pointed out that as elevators already "talk" to their passengers, it would be logical that passengers could also speak to them. Some of the experts also suggested that the possibility of "pulling down" an interface or a screen by hand would be useful for people of different heights.

\subsection{Ideas and Opportunities}

The experts' ideas about the potential applications and locations for media surfaces were explored both in the prototype and in the design game. Some of the experts considered the surface to be particularly entertaining for children. However, they also felt that adults would gladly spend time in front of it. One of the experts stated that the hygienic aspect of the interaction was a particularly positive quality. According to her, the possibility of interacting with the surface without touching it is important. It would be extremely useful in hospitals, as well as generally for people who need to avoid the possibility of becoming infected. The interactive feature of the prototype could also be beneficial in private homes for people who are elderly or who have significant mobility difficulties. They could control their home by hand, or even with their fingers, if the sensors on the surface were adjusted accordingly.

The surface was also regarded as offering potential in enabling and enhancing social interaction for people who live far away from each other. Collaborative activities could reinforce relationships and create a sense of community and belonging. The experts also highlighted opportunities for fostering well-being, for example, by "nudging" specific emotions through a media surface. They proposed a mood wall that could reduce stress or increase happiness, as well as calm or energise. The prototype and similar products could also be helpful in pathfinding, guiding and informing at large. The possibility of automatically recognising that a person uses an assistive product, and providing instructions for an accessible route, were highlighted as an example in the design game. Colours could be used as identifiers in different locations. In addition to these examples that make everyday life easier, news updates and weather forecasts were highlighted as interesting additional features. In general, the experts hoped for contents that would evoke positive thoughts and emotions. Based on the image cards they were shown in the design game, wildlife would be a particularly desirable theme.

According to the experts, the media surface could be located in public lobbies, in different kinds of waiting areas, whether in hospitals, stations or at airports, in shopping centres and various shops, in libraries, or other locations, where it could function as a leisure activity.

Some of the experts suggested that the media surface could include music that would be compatible with the associations created by the moving colours and lights. One expert, 
who used a powered wheelchair, felt like dancing as he associated some of the colours and their movements with a disco. He moved his upper body according to the rhythm of the colours and lights.

Whether the prototype or similar products could offer or use personal information raised concerns among the experts. Measuring people, for example, their bodily functions, and adjusting their environment accordingly was regarded as an interesting opportunity. However, the experts stated that evoking negative emotions or providing unwanted information was rather risky. Nevertheless, providing your own content and adjusting the service to suit your own preferences were considered essential and something to strive for. The experts were concerned about the privacy, security and potential misuse of personal data. Having control over what information is shared with others, particularly if it is automatically retrieved from personal devices, was described as being important.

\section{Discussion and Conclusions}

\subsection{Product Qualities and Purposes of Use}

In summary, the experts by experience highlighted colours, contrasts, brightness, movements, associations and purposes of use as issues that influenced their experience of the prototype, in particular, its interactive media surface. Blueish colours and light colours were perceived as calming, reddish and bright colours were perceived as energising, and a tinted yellow as the most pleasant. The colour hue and temperature had an effect on how the colours were regarded. Sharp contrasts were considered unpleasant. However, sufficient contrast as well as light was needed for good usability and accessibility.

Concerning the ways in which the lights and colours moved - slow, regular and upward or downward movements were regarded as being more pleasant than fast, irregular and lateral movements. Slow movements were considered relaxing, fast movements energetic and zigzag movements restless. Movements that were predictable and have a sense of direction were highlighted as something to strive for in design. Both the individual colours and the combinations of colours, lights and their movements were associated with different kinds of places, atmospheres, elements and phenomena.

When asked about the potential applications for the prototype and similar products, the experts by experience suggested the following: a playful leisure activity or form of entertainment, a means of enhancing well-being, an enabler of social interaction and sense of belonging, a channel for creativity, as well as an informing and guiding setting for increasing independence. Potential locations included public places where people spend time. Also, private homes were mentioned as places in which interactive media surfaces could enable independent living.

Interacting with the prototype, and particularly controlling it by hand, was regarded as exciting, even as fun. However, in addition to a manual control, the experts by experience wanted a complementary voice control to increase accessibility and enhance the multisensory experience. Moreover, they hoped there would be an option to adjust the settings and provide content by themselves in a way that would be safe, including in terms of privacy. 


\subsection{Design Drivers for Multisensory Experience}

Based on the findings of the user study, the experience that the experts appreciated the most in an elevator car with an interactive media surface was a calm and temperate one. In order to provide users with such an experience, an interactive media surface should include the following:

- blue colours, or alternatively tinted yellow

- nature-related or -inspired themes

- $\quad$ soft contrasts and moderate brightness without compromising accessibility

- $\quad$ predictable, upward or downward movements, or alternatively slowly twinkling lights

- $\quad$ subtle instrumental music

- a sufficiently sensitive manual control

- voice as a complementary means of controlling the surface

- no scent, or only a subtle one

- $\quad$ settings that can be adjusted by users

- contents based on users' individual requirements

- secured use of private information.

It should be noted that the proximity of the media surface appears to influence the experience. A closer proximity may enhance the immersiveness of the experience but, at the same time, the ability to recognise shapes and movements becomes limited.

\subsection{The Experts' Experiences and Insights}

The findings of the user study reveal how the experts by experience, who were users with physical disabilities and visual impairments, and were trained to take these into account, regarded the prototype. In the thinking aloud task, they readily expressed what they felt. They focused on product qualities that contributed to a holistic multisensory experience and pinpointed those product qualities that worked well and those that did not. The design game supported and concretised the experts' input. It enabled them to ponder the role of media surfaces in their everyday life, and it triggered a deeper and richer thinking and ideation process.

When observing the experts, it became evident that when all senses are not being fully utilised, the importance of the other senses increases. This influences both perception and experience. The findings show that engaging participants who have diverse abilities in terms of both moving in the built environment and in sensing its various qualities is important, as multisensory cues may be difficult to detect and distinguish if all senses and parts of the body are being used.

In addition to providing their evaluative feedback on the prototype's current qualities, the experts by experience contributed to the project team's work with insights into improving the prototype and envisioning similar products in the future. Thus, not only were they able to consider the existing product properties, but also ideate new properties, for example, purposes of use. The prototype showed that it is important to involve a diversity of users as early as the research and development phase because in the subsequent phases, the main design decisions are likely to have already been made. If users are only involved in a later phase, their feedback may be disconnected and formal. 
It could reduce user participation to mere manoeuvring. This has reportedly sometimes happened when developing public health care, as was highlighted in the introduction.

With regard to the user study, there were practical issues that might have affected the outcome. The location at which the user study was organised turned out to be rather loud and busy. It was occasionally difficult to hear the experts as a result of various construction noises. However, observations made by several researchers and recordings helped overcome this issue. On the other hand, such an intensive environment could support the study's research and development context and perhaps convince or even inspire the participants and place them more firmly in their role as experts.

\subsection{The Value of Involving Experts by Experience}

When designing products, whether they are artefacts, spaces, environments, services or systems, to be used by the widest range of people, persons with different kinds of characteristics and experiences should be included in user studies. Any users with diversity can contribute to research and development. However, the findings of this study indicate that trained experts by experience can be particularly skilful in evaluating products. They can readily adopt a role in which they can focus on the essential qualities of a product, and also provide feedback about them.

Experts by experience tend to emphasise experience-related issues, which is their strength and the value-adding reason for involving them. In this study, particular emphasis was placed on accessibility and assistive features due to the experts' experience of living with a disability that mostly affects mobility. This was so innate to some of the experts that the researchers occasionally also needed to specifically ask about other issues in order to learn about the holistic user experience.

As previously discussed, elevators have to meet the accessibility requirements set by the most extreme users. In doing so, they are likely to also meet the needs of those people who are between the extremes. Experts by experience can detect the inclusive and universal qualities that benefit all users. In addition to accessibility, they can also make other observations that relate to, for example, creating an atmosphere and well-being, which are relevant to everyone. In this study, the experts' input was well in line with the aims and guidelines set by universal and inclusive designs.

Based on the findings, involving experts by experience in research and development can be seen as an example of social sustainability and responsibility in a corporate context. For a company, it is not only a way of showing that it recognises the importance and value of diverse users but is also a means of actually including and empowering them. It is a concrete way of putting justice, equality and the possibility of influencing into practice. In this study, engaging experts by experience increased the project team's awareness of the diversity of users and, importantly, their empathy. The experts could raise new perspectives and issues, whose existence was not previously known to everyone involved.

The study described and discussed in this paper has been exploratory. At the time of writing the paper, the author is not aware that trained experts by experience have been previously engaged in research and development in large companies in Finland, even though diverse users, including people with disabilities, have generally participated in user studies. Based on the discussion triggered by the study findings, the chosen approach seems to be something new and potential. It could be one way of channelling the corporate ambition in social sustainability and responsibility. However, outlining the long-term strategic value of involving experts by experience requires further studies. 


\section{Acknowledgements}

The author would like to thank the anonymous reviewer for their valuable comments, which helped to improve the paper. The author also expresses her gratitude to the experts by experience for participating in the study, and her colleagues at KONE, in particular Rasmus Lönnqvist and Anna Klemettilä-Sorri for helping with the testing of the prototype, Saga-Sofia Santala and Reetta Turtiainen for carrying out the design game, and Dr. Sanni Siltanen for giving feedback on the paper. Regarding the construction of the prototype, the author would like to thank Jukka Korpihete, Otto Urpala and Tony Yau at KONE and Dr. Kimmo Keränen and Dr. Tuomas Happonen from the VTT Technical Research Centre of Finland. Above all, the author is grateful to Jaana Hyvärinen for the opportunity to participate in the InSCOPE project. The project received funding from the European Union's Horizon 2020 research and innovation programme under grant agreement no. 731671.

\section{References}

[1] InSCOPE. Project. Retrieved 10 Feb 2021 from https://inscope-project.eu/project/

[2] KONE. Company. Retrieved 11 Feb 2021 from https://www.kone.com/en/company/\#item-101800

[3] KoKoA. Koulutetut Kokemusasiantuntijat ry. Retrieved 10 Feb 2021 from http://www.kokemusasiantuntijat.fi/

[4] S. Jacobson. Personalised Assistive Products: Managing Stigma and Expressing the Self. Aalto University publication series doctoral dissertations, 1/2014. Helsinki: Aalto University School of Arts, Design and Architecture, 2014. Retrieved 10 Feb 2021 from https://aaltodoc.aalto.fi/handle/123456789/13321

[5] O. Hietala \& P. Rissanen. Kokemusasiantuntija - hoidon ja avun kohteesta omien kokemusten jakajaksi sekä palveluiden kehittäjäksi. Opas kokemusasiantuntijatoiminnasta. Helsinki: Kuntoutussäätiö \& Mielenterveyden Keskusliitto, 2015. Retrieved 10 Feb 2021 from https://kuntoutussaatio.fi/files/1944/kokemusasiantuntija-opas.pdf

[6] H. Palukka, T. Tiilikka \& P. Auvinen. Kokemusasiantuntija mielenterveys- ja päihdepalveluissa Osallisuuden mahdollistaja vai osallistamispolitiikan väline? Janus 27(1) (2019), 21-37. Retrieved 10 Feb 2021 from https://journal.fi/janus/article/download/66252/40484

[7] T. Meriluoto. Making Experts-by-experience - Governmental Ethnography of Participatory Initiatives in Finnish Social Welfare Organisations. JYU dissertations 38. Jyväskylä: University of Jyväskylä, 2018. Retrieved 10 Feb 2021 from https://jyx.jyu.fi/bitstream/handle/123456789/60096/978-951-397603-3_vaitos24112018.pdf?sequence=1\&isAllowed $=\mathrm{y}$

[8] E. Kostiainen, S. Ahonen, T. Verho, P. Rissanen \& T. Rotko. Kokemukset käyttöönkokemusasiantuntijatoiminnan kehittäminen. Työpaperi 36 (2014). Helsinki: Terveyden ja hyvinvoinnin laitos. Retrieved 10 Feb 2021 from http://www.julkari.fi/bitstream/handle/10024/125488/URN ISBN 978-952-302-373-4.pdf?sequence=1

[9] M. Kautto \& L. Metso. Sosiaalinen kestävyys - uusi poliittinen hōisontti? Yhteiskuntapolitiikka 73(4) (2008), 411-420. Retrieved 10 Feb 2021 from https://www.julkari.fi/bitstream/handle/10024/101009/kautto.pdf?sequence=1\&isAllowed=y

[10] SFS-EN ISO 9241-210:2019:en. Ergonomics of human-system interaction, Part 210: Human-centred design for interactive systems (ISO 9241-210:2019). $2^{\text {nd }}$ edition. Helsinki: Finnish Standards Association SFS.

[11] UN Global Compact. Social Sustainability. Retrieved 10 Feb 2021 from https://www.unglobalcompact.org/what-is-gc/our-work/social

[12] UN Sustainable Development Goals. Retrieved 10 Feb 2021 from https:/www.un.org/sustainabledevelopment/sustainable-development-goals/

[13] KONE. Helping Cities Grow Sustainably. Sustainability Report 2019. Retrieved 10 Feb 2021 from https://www.kone.com/en/Images/KONE_Sustainability_Report_2019_tcm17-91172.pdf

[14] T. Keinonen, J. Andersson, J.-P. Bergman, S. Piira \& M. Sääskilahti. Mitä tuotekonseptointi on? In T. Keinonen, \& V. Jääskö (Eds.), Tuotekonseptointi. Teknologiateollisuuden julkaisuja nro 12/2003. Helsinki: Teknologiateollisuus ry, 2003, 9-47. 
[15] European Disability Forum. Design for All. Retrieved 16 Jan 2020 from http://www.edffeph.org/design-all1 1

[16] EN 301 549. Accessibility requirements suitable for public procurement of ICT products and services in Europe. Retrieved 8 Aug 2019 from http://mandate376.standards.eu/standard

[17] N. A. Jalil, R. M. Yunus \& N. H. Said. Environmental Colour Impact upon Human Behaviour: A Review. Procedia - Social and Behavioral Sciences 35 (2012), 54-62.

\title{
Illustrations
}

Figures 1-3, 6-10. Pictures drawn and snapshots of video recordings taken and anonymised by Rasmus Lönnqvist.

Figures 4-5. Photographs by Saga-Sofia Santala.

\begin{abstract}
About the Author
Dr. Susanne Jacobson currently works as an expert in design research at KONE Corporation. Her specialties include user experience, user innovation and design semantics. She has taken an interest in what using products means, how users identify themselves with products and become attached to them. She holds a Doctor of Arts degree (2014) in Industrial and Strategic Design from the Aalto University School of Arts, Design and Architecture, Finland. In her doctoral research, she focused on personalisation as a means of managing the stigma associated with assistive technology use and accessibility.
\end{abstract}

